\title{
An Analysis of Non-Integrated Engineering Education
}

\author{
Katherine E. Sukel, Mark Guzdial, Matthew Realff, Pete Ludovice, and Tom Morley \\ Georgia Institute of Technology, Atlanta, GA 30332 \\ Tel: 404-894-3152, Fax: 404-385-1253 \\ Email: kayt@cc.gatech.edu; guzdial@cc.gatech.edu; matthew.realff@che.gatech.edu; \\ pete.ludovice@che.gatech.edu; thomas.morley@math.gatech.edu
}

\begin{abstract}
This paper will discuss the efforts of the Computer-Modeling for Curriculum Integration (CMCI) Project to measure undergraduate engineering students' integration of crossdisciplinary information. This will include a description of the method we used to measure integration, as well as our findings. This will be followed by a brief discussion of the web-based tools we are developing in order to facilitate integrative learning in the engineering curricula.
\end{abstract}

Keywords: curriculum, educational reform, learning communities, quantitative assessment.

\section{Introduction}

The original goal of the American University was to successfully integrate the ideal of the British undergraduate education experience with that of the German focused research institution (Cuban, 1999). However, as universities moved away from a one-on-one advising model to a standardized curriculum, students are now required to take courses for which they do not understand the purpose (Donald, 1997).

From a cognitive perspective, we know that it is important for students to see the connections between knowledge areas in order to transfer knowledge between situations (Singley \& Anderson, 1989). Without those connections, students develop "brittle knowledge," where knowledge is only understood within a given, specific context. Students need to develop more general indices for their knowledge so that it can be applied in novel situations (Kolodner, 1993). So the question is, do engineering students integrate knowledge across mathematics and engineering, despite a standardized curriculum?

\section{Measuring Levels of Integrative Learning}

In order to address integrative learning within the engineering curricula at Georgia Institute of Technology (Georgia Tech), we decided to contrast different types of problem contexts and problem calculations. The logic behind this experimental design is that students who are successfully integrating knowledge across disciplines should be able to complete problems of varying context and calculation. Further details about this study and its results can be found in Sukel et al. (2000), submitted for publication.

\section{Participants}

Thirty-two participants were recruited from Chemical Engineering and Mathematics classes at Georgia Tech. Participants were racially diverse, and ranged from Sophomores to Seniors. Half of the participants were chemical engineering majors, with smaller numbers of other types of engineering majors making up the difference.

\section{Materials}

We designed a test of nine problems, which included all iterations of mathematics, chemical engineering, and numerical methods problem contexts and problem calculations. Numerical Methods calculations were represented by the common Engineering modeling language, Matlab, calculations.

\section{Procedure}

Participants were tested in groups in a testing room. Each participant was seated individually at a desk and asked not to talk or discuss problems with any of the other participants as they worked through the problems. Additionally, participants were asked to note the time they started and completed each problem, as well as to attempt to answer each problem to the best of their ability in a 2 hour time period. Furthermore, if they were for some reason unable to answer the problem, they were instructed to discuss the method they would have used to solve it, or explain their inability to solve it. 


\section{Results}

If there was integrated learning, we would expect that students would perform similarly within a context despite the calculation, within a calculation despite the context, or similarly over all. But instead, we found significant differences. A significant main effect of calculation was found, $\mathrm{F}(2,62)=4.49$, MSE $=7.35, p=.02$, where participants scored higher on problems with mathematical calculations over chemical engineering and Matlab calculations. There was a significant interaction of context and calculation, $\mathrm{F}(4,124)=10.58$, MSE $=21.58, p<.01$. This interaction was driven by participants scoring higher on consistent context and calculation problems (e.g., chemical engineering context, chemical engineering calculation) across chemical engineering and numerical methods areas.

Neither sex, race, GPA or major, when added as an additional variable, constituted a significant difference. Participants scored higher on problems that were consistent across context and calculation. Surprisingly, matching a major and a context was not a guarantee of success. In fact, Electrical Engineering (EE) majors did better on Chemical Engineering context problems than did Chemical Engineers! This effect may be due to the fact that Electrical Engineers are better at transferring mathematical knowledge across contexts.

\section{Discussion}

The results are somewhat disappointing, though not suprising. In general, students were able to solve problems well when the context and calculation matched well. But where they did not, performance was disappointing. Students' performance in numerical methods is particularly disappointing, considering the importance of these kinds of problems in professional engineering practice. The results suggest that students are not integrating their knowledge across the multiple classes and years of their Engineering curriculum.

There are caveats to these results. It could have been that the mixed context-calculation problems were harder than the same context-calculation problems. However, the consistency of the results suggests otherwise.

In order to improve integrative learning, we are exploring a solution utilizing collaborative learning technologies. We have created a collaborative space (a CoWeb for Collaborative Website) which is being used by classes in Chemical Engineering, Mathematics, and Computer Science at the same time, when those classes address the common theme of "computer modeling in MATLAB." There are three goals for the space: (1) creating a resource for students to aid in solving computational modeling problems; (2) making the space open to collaboration so that students interact with one another on homework assignments and help to answer each other's questions; and (3) developing creative ways to help students recognize cross-disciplinary connections by the design and linking of the various pages on the CoWeb.

\section{References}

Astin AW, Green KC, \& Korn WS (1987). The American Freshman: Twenty year trends. Los Angeles: Cooperative Institutional Program of the American Council on Education and the University of California.

Cuban, L (1999). How the Scholars Trumped the Teachers. New York: Teachers College Press.

Donald J (1997). Improving the Environment for Learning: Academic Leaders Talk About What Works. San Francisco: Jossey-Bass.

Kolodner J (1993). Case Based Reasoning. San Mateo, CA: Morgan Kaufmann Publishers.

Sukel KE, Guzdial M, Realff M, Ludovice P, \& Morley T (2000). Measuring and Improving Non-Integrated Engineering Education. Submitted for publication as a GVU Technical Report.

Singley MK, \& Anderson JR (1989). The Transfer of Cognitive Skill. Cambridge, MA: Harvard University Press.

Williams TR, \& Schiralli M (1991). Canadian University Presidents' perceptions on campus life issues. Paper presented at the Annual Conference of the Canadian Society for the Study of Higher Education, Kingston, ON.

\section{Acknowledgments}

This research is supported by a grant from the National Science Foundation, REC-9814770, by an AEG grant from Sun Computer, and by seed funding from Siemens and the GVU Center at Georgia Tech. 